\title{
A Linear Programming Based DEA-PROMETHEE Approach for \\ Performance Evaluation
}

DOI:10.36909/jer.13279

Uğur Tahsin Şenel*, Babak Daneshvar Rouyendegh (B.Erdebilli) ${ }^{* *}$, Adem Pınar ${ }^{* * *}$

*Department of Industrial Engineering, Ankara Yıldırım Beyazıt University, 06010 Ankara, Turkey

** Department of Mechanical \& Industrial Engineering, College of Engineering Sultan Qaboos University, Oman

*** Turkish Land Forces Logistics Command, 06135 Ankara, Turkey

*Corresponding Author: utsenel@gmail.com

\begin{abstract}
Companies follow their objectives with some critical success factors (CSF), and they know their bottlenecks and strong points. This provides decision support for them, but this method ignores overall performance and ranking issues. In this study, a comprehensive methodology is recommended to find out an effective solution to the performance evaluation problem for making strategic performance management. Two methods are used from different areas as a framework. To select the higher-performing departments, Data Envelopment Analyses (DEA) is used as a linear programming-based main method. Moreover, a Multi-Criteria Decision Making (MCDM) method is proposed, Preference Ranking Organization Method for Enrichment Evaluations (PROMETHEE), to increase the discrimination power of DEA and eliminate undesirable results because of determining weight bounds. These two methods are combined, and a comprehensive solution model is presented in the study. In the end, a case study is given for a real-life example, an integrated DEA-PROMETHEE method is applied to the case. When the case results are examined, the proposed model produces more logical weight values and better results.
\end{abstract}


$\begin{array}{llll}\text { Keywords: } & \text { Multi-criteria making } & \text { decision } & \text { MCDM); }\end{array}$

PROMETHEE; Data envelopment analyses (DEA); Critical success factors (CSF); Performance ranking

\section{INTRODUCTION}

Recent developments in world trade lead to raising the importance of enterprise management activities. Companies need more caution about their decisions. Therefore, they do more analyses and focus on the critical success factors. These critical success factors (CSF), sometimes called a key performance indicator, reflect the company's current position and helps to make the next decisions. They ensure the strategic management perspective because each CSF is determined in terms of strategic goals. Therefore, actualizations of objectives point out the success degree. To trace these CSFs and understand the success degree of the company and sub-departments or branches' performance, different performance management tools are suggested in the literature such as balanced scorecards, Performance Pyramid, Strategic Measurement Analysis, and Reporting Technique (SMART).

Strategic Management tools ensure correct points for upper management levels but they are not enough to demonstrate overall performance. Fair evaluation and CSF preference have also an important role to follow strengths and weaknesses (Yurdakul and Ic, 2005). To handle this problem, Senel et al. (2019) recommend a comprehensive method including strategic performance management, efficiency analyses, and success grouping. When this study is examined, they suggest Data Envelopment Analyses (DEA) for efficiency analyses as a frame of the study. It could be seen that DEA weight values affect results directly. It is considered that if this weight value determination process is improved, then the discrimination power of DEA raise and better results are obtained.

With this study, we offer a DEA model enriched by the Preference Ranking Organization Method for Enrichment Evaluations (PROMETHEE). Our model is applicable for any 
company that follows CSFs and afford to manage performance. Using this approach, DEA works more correctly to determine efficient DMUs and prevent undesirable results caused by meaningless weight values. In the model, we used two different DEA approaches. The first approach was developed by Charnes et al. (1978), called CCR. The other approach was developed by Banker et al. (1984), called BCC. For these two models, weight restrictions are determined in terms of PROMETHEE results.

As a literature review; regarding performance evaluation, Sousa et al. (2020) studied an overview of academic literature on Balanced Scorecard for performance evaluation of supply chains. Tekez et al. (2019) focus on performance evaluation of suppliers, using Enterprise Resource Planning to collect and track real-time data for supplier evaluation systems. Senel et al. (2020) suggest a comprehensive performance management approach taking into consideration both effectivity and efficiency perspectives. In the model, Balanced Scorecard for strategic management and effectivity analyses, Analytic Hierarchy Process (AHP) for weights, Data Envelopment Analyze (DEA) for efficiency analyze and Clustering Techniques for grouping DMUs are used to obtain overall success. Senel (2020) improved this study by adding different DEA types such as input-output oriented CCR, input-output oriented BCC, and weighed CCR, having AHP results as weights.

Aladag et al. (2018) used both DEA and PROMETHEE methods separately for academic unit performance evaluation. In the study, super efficiency scores of DEA applications are compared with PROMETHEE application results using Spearman Correlation. Although Aladag et al. (2018) both methods are successful for complete ranking, ranking results are different. It shows that methods have some different flaws because of mathematical structures and focusing points. DEA focuses on selecting efficient units and has output or input orientation. It is also affected the number of DMUs more than the PROMETHEE. 
Babaee et. al. (2015) studied an assessment of older drivers' performance. They apply DEA and PROMETHEE II models separately and point out that there is a high correlation between the two methods. They showed model results in robustness with these two methods. They suggest studying a combination of DEA and PROMETHEE.

Bagherikahvarin (2016) used DEA and PROMETHEE methods in Aladag et al.'s (2018) study. First, DEA application is applied for each DMU pair, then, the results of DEA are used as input of PROMETHEE pairwise comparison matrix. Here, cross-efficiency values are compared. This work is compared with only DEA scores, and it is shown that the integration of DEA and MCDM causes to obtain more sensitive results for complete rankings.

Bagherikahvarin and Smet (2016) studied DEA and PROMETHEE II methods integration for a ranking problem. They discussed deficiencies of DEA because of weight independence. When weights are not defined or constrained results could be different from the expected. Higher or lower weight values cause a weak determination of efficient DMUs. In some cases, unreasonable units could be efficient because of unreasonable weight values. Therefore, they suggest the restricted DEA model. They restrict the weight values using the PROMETHEE II method. Their pilot case shows how can PROMETHEE integrate into DEA. On the other hand, their second contribution is using a single input and all criteria as output for the ranking issue.

There are lots of MCDM studies in the literature to make comparisons among the DMUs in terms of performance success. Senel (2018) used integration of AHP and ELECTRE methods. AHP results provide weights values for pairwise comparison in the ELECTRE. The study shows that MCDM methods are insufficient to make complete rankings from the resource usage perspective. It is recommended to integrate a linear-based method to obtain more successful rankings. Senkayas and Hekimoglu (2013) used the PROMETHEE method for the selection of the most attractive supplier. They used different Preference Function Types and 
also suggest that different MCDM methods could be tried to have more appropriate results for DM. Albadvi et. al. (2007) uses the PROMETHEE method on stock trading which means collecting the right amount of stock on hand. They implied that the PROMETHEE method is easier and reliable than the other methods in terms of scope and application. It enables also a detailed analyses opportunity

There are also many studies on integration between MCDM and DEA. Rouyendegh's (2011) DEA results (efficient /not efficient) are not enough for a fair comparison. Using results, Intuitionistic Fuzzy (IF) TOPSIS method is applied to full ranking. Thanks to IF TOPSIS, decision-makers could affect the ranking process. Najafi and Aryanezhad (2011) compare differences between DEA and Balanced Scorecard (BSC), which is a strategical management tool. They assert that both perspectives are important for measuring performance. They calculated BSC weight values in terms of the AHP method. BSC key performance indicators are categorized as input and output for DEA and a complete ranking is made.

In the next chapter, we obtained more information about the MCDM techniques and DEA applications and prepared a methodology for problem-solving. After, demonstrating the application of the developed model, we present a case study. In the conclusion, study findings and outputs are commented on. All in all, references are attached at the end of the paper.

\section{METHODOLOGY}

As a methodology, we used PROMETHEE and DEA methods respectively. First, we apply PROMETHEE to determine the DEA weight restriction values. After, the DEA method is applied to determine relative efficiency scores.

\section{Preference Ranking Organization Method for Enrichment Evaluations (PROMETHEE)}

The Preference Ranking Organization Method for Enrichment Evaluations (PROMETHEE) method was developed by Brans (1982). It is one of the commonly used MCDM methods, 
famous for easy utilization. The method provides partial, called PROMETHEE I, and complete rankings, called PROMETHEE II. The approach depends on pairwise comparisons according to criteria priorities. Moreover, each criterion has weight values showing its importance. On the other hand, there are six types of evaluation factors to compare criteria. It is also a highlighted point of the PROMETHEE method because it ensures a large evaluation opportunity to a different type of criteria (Şenkayas and Hekimoglu, 2013). There are six types of preferences functions given in Table 1. 
Table 1. Preference Functions (Brans and Smet, 2016)

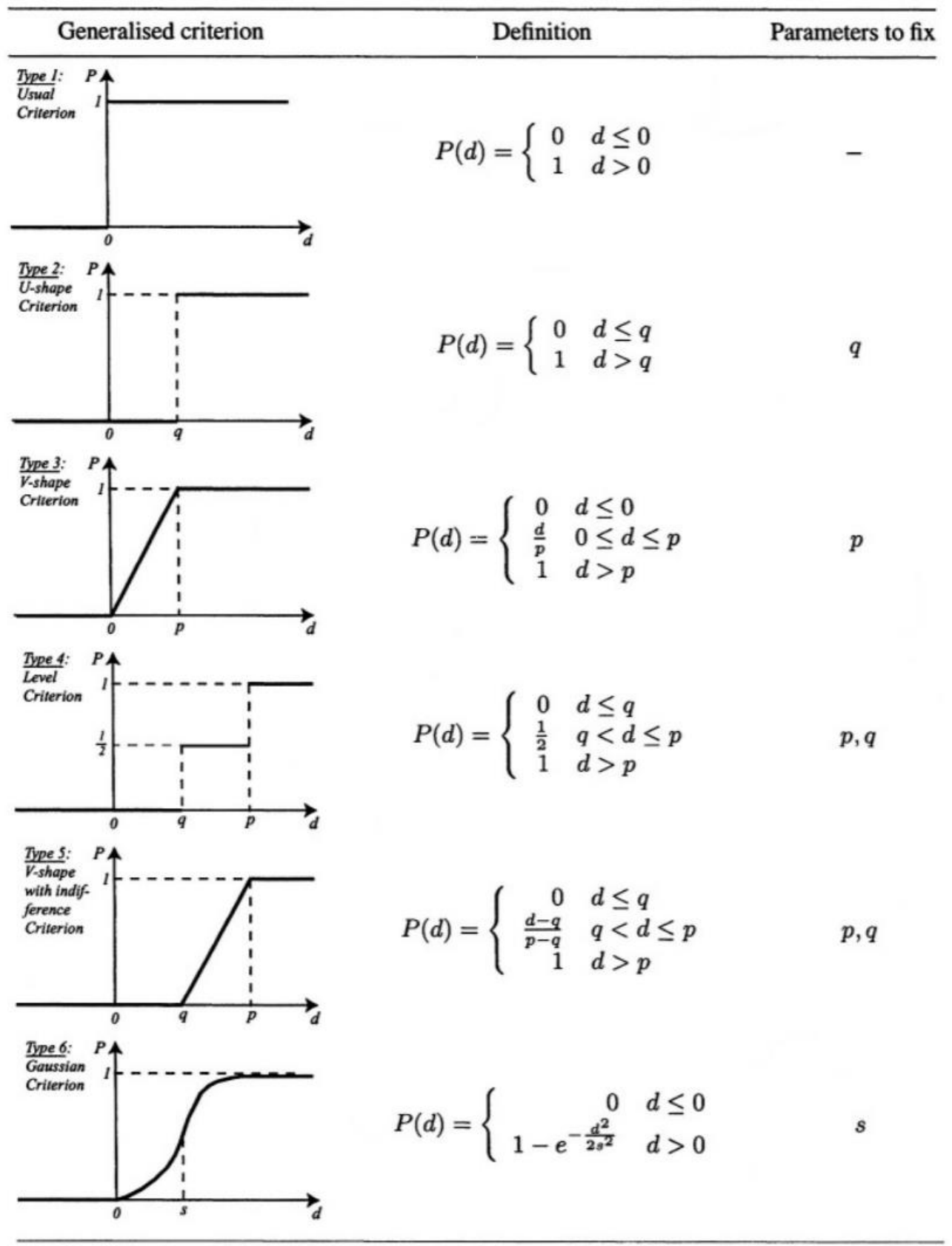

Using one of these functions, preference values are determined between criteria (Brans and Smet, 2016). In the model, $g_{j}$ represents the criteria, $p j$ indicates preference function and $w_{j}$ shows weights. $(a, b)$ is multicriteria preference degree of $a$ over $b$. Equations (1) to (6) give the PROMETHEE process (Safari et al., 2012). 


$$
\begin{gathered}
\pi(\mathrm{a}, \mathrm{b})=\frac{\sum_{\mathrm{j}=1}^{n} w_{j} p_{j}(a, b)}{\sum_{\mathrm{j}=1}^{n} w_{j}} \\
\emptyset^{+}(a)=\sum_{\mathrm{i} \in \mathrm{A}} \pi(\mathrm{i}, \mathrm{a}) \\
\emptyset^{-}(a)=\sum_{\mathrm{i} \in \mathrm{A}} \pi(\mathrm{a}, \mathrm{i}) \\
\emptyset^{+}(a)=\emptyset^{+}(a)-\emptyset^{-}(a) \\
f_{\mathrm{a} \in \mathrm{A}} \emptyset^{+}(a) \\
f^{-}(a)=\frac{1-\emptyset^{-}(a)}{\sum_{\mathrm{a} \in \mathrm{A}} 1-\emptyset^{-}(a)}
\end{gathered}
$$

In the model, $\emptyset^{+}$is called leaving flow and demonstrates strength. $\emptyset^{-}$is called entering the flow and demonstrate weakness. $\emptyset$ is called net flow. For the decision process, if $\Phi$ (a) is greater than $\Phi$ (b) means that a is better than b if $\Phi$ (a) equals to $\Phi$ (b) means that both alternatives are equal and lastly, if $\Phi(\mathrm{b})$ is greater than $\Phi(\mathrm{a})$ has the meaning of $b$ is a better option than a. In this study, we use complete partial values of PROMETHEE processes including $\emptyset, \emptyset^{+}$and $\emptyset^{-}$

In the model, our contribution is to normalize leaving and entering flows because we want to form them to use for the DEA procedure. Thanks to normalization each weight value is in the range of $\% 0$ to $\% 100$. Therefore, we computed $f^{+}$and $f^{-}$values, the formulation is given on the in formula 3.5 and 3.6 respectively. Another contribution is made for the determination of lower and upper weights degree. For this, $\min \left(f^{+}, f^{-}\right)$gives the lower degree, in contrast, $\max \left(f^{+}, f^{-}\right)$calculates the upper degree of DEA weight variables.

\section{Data Envelopment Analyse (DEA)}

Data Envelopment Analyse (DEA) method, developed by Charnes et al. (1978), was used to measure the performance of public organizations at the beginning, such as schools, hospitals. Over the years, it is commonly used for performance analysis in different product and service 
sectors. Since the methodology is based on linear programming and non-parametric, it is one of the most reliable and consistent approaches for relative efficiency comparison.

In the DEA model, there are two main parameters, $x_{i k}$ and $y_{r k}$. While $x_{i k}$ indicates the value of inputs used by DMU $k, y_{r k}$ represents the value of outputs produced by DMU $k$. Besides, there are two main variables in the calculation, $u_{r}$ and $v_{i} . u_{r}$ represents the weights of inputs, and similarly, $v_{i}$ represents the weights of outputs. These elements form the frame of the DEA model. Equation (7) shows the objective function of the model. The objective of DEA is to maximize outputs in terms of constrained inputs. It can be stated that the sum of weighted outputs divided by the sum of weighted inputs gives the objective. This model is constructed for $m$ inputs, $\mathrm{n}$ outputs, and d DMUs. $Q_{0}$ is the objective function value, efficiency score, of the chosen DMU for comparison. Efficiency scores must be smaller or equal to 1 . If it is equal to 1 , it shows DMU is relatively efficient, otherwise it is called not relatively efficient. In Equation (8) other DMUs' efficiency scores from chosen DMU are restricted by 1 . Equations (9) and (10) show the weight value constraints.

$$
\operatorname{Max}\left\{Q_{0}=\frac{\sum_{r=1}^{n} u_{r} y_{r 0}}{\sum_{i=1}^{m} v_{i} x_{i 0}}\right\}
$$

Constraints;

$$
\begin{array}{cc}
\frac{\sum_{r=1}^{n} u_{r} y_{r k}}{\sum_{i=1}^{m} v_{i} x_{i k}} \leq 1 & \mathrm{k}=1 \ldots \mathrm{d} \\
u_{r} \geq 0 & \mathrm{r}=1 \ldots \mathrm{n} \\
v_{i} \geq 0 & \mathrm{i}=1 \ldots \mathrm{m}
\end{array}
$$

In the literature, several approaches are used to linearize the DEA model. CCR and BCC models are used commonly for this aim. CCR model, measuring global efficiency, moves the objective function denominator to the constraints having a value of 1, given at Equation (12). Equation (8) also changes into Equation (13). Lastly, our last contribution to the model, 
restricted weight values obtained by the PROMETHEE process, are given in Equations (14) and (15).

$$
\begin{array}{cl}
\operatorname{Max}\left\{Q_{0}=\sum_{r=1}^{n} u_{r} y_{r 0}\right\} & \\
\sum_{i=1}^{m} v_{i} x_{i 0}=1 & \\
\sum_{r=1}^{n} u_{r} y_{r k}-\sum_{i=1}^{m} v_{i} x_{i k} \leq 0 & \mathrm{k}=1 \ldots \mathrm{d} \\
f^{+}(r) \geq u_{r} \geq f^{-}(r) & \mathrm{r}=1 \ldots \mathrm{n} \\
f^{+}(i) \geq v_{i} \geq f^{-}(i) & \mathrm{i}=1 \ldots \mathrm{m}
\end{array}
$$

Banker et al. (1984) developed the BCC model as an alternative to the CCR model. In terms of the BCC model, measuring local efficiency, there is an extra variable, $u_{0}$, that ensures the flexibility of efficiency detection. It is extracted from the objective function and the balancing constraint of inputs and outputs. The BCC model, including our contribution, is given between Equations (16) and (20).

Objective;

$$
\operatorname{Max} Q_{0}=\sum_{r=1}^{n} u_{r} y_{r 0}-u_{0}
$$

Constraints;

$$
\begin{array}{cc}
\sum_{i=1}^{m} v_{i} x_{i 0}=1 & \\
\sum_{r=1}^{n} u_{r} y_{r k}-\sum_{i=1}^{m} v_{i} x_{i k}-u_{0} \leq 0 & \mathrm{k}=1 \ldots \mathrm{d} \\
\emptyset^{+}(r) \geq u_{r} \geq \emptyset^{-}(r), u_{0} \text { is free } & \mathrm{r}=1 \ldots \mathrm{n} \\
\emptyset^{+}(i) \geq v_{i} \geq \emptyset^{-}(i) & \mathrm{i}=1 \ldots \mathrm{m}
\end{array}
$$

\section{CASE STUDY}

The methodology suggested by us is applied for ranking 5 departments, called DMU, belonging to an enterprise company. 8 CSF's are used as criteria. Criteria actualization values 
are obtained by the company. Since the security issues, criteria, and DMU names will not be explained. They are abbreviated as $C_{n}$ and $D_{n}$ respectively. Values are also normalized.

In the procedure, these 8 criteria are compared in the PROMETHEE step. At this point, pairwise CSFs are evaluated according to 4 decision-makers. Results of the PROMETHEE are the inputs of the DEA procedure as weight constraints. Applications are made on Microsoft EXCEL.

\section{Weight restrictions: PROMETHEE}

In the PROMETHEE procedure, we surveyed 8 CSFs for an enterprise company. In terms of company rules, we do not authorize for sharing names of the CSFs. 4 performance management specialists evaluated the CSFs. In Table 2, we shared the comparison results. Ci demonstrates CSFs and $\mathrm{Sj}$ shows performance management specialist evaluations.

Table 2. CSF Comparison Results

\begin{tabular}{|c|c|c|c|c|}
\hline $\mathbf{C i} / \mathbf{S j}$ & $\mathbf{S 1}$ & $\mathbf{0 S 2}$ & $\mathbf{S 3}$ & $\mathbf{S 4}$ \\
\hline $\mathbf{C 1}$ & $5 \%$ & $5 \%$ & $5 \%$ & $8 \%$ \\
\hline $\mathbf{C 2}$ & $35 \%$ & $25 \%$ & $27 \%$ & $30 \%$ \\
\hline $\mathbf{C 3}$ & $20 \%$ & $20 \%$ & $23 \%$ & $16 \%$ \\
\hline $\mathbf{C 4}$ & $7,5 \%$ & $10 \%$ & $6 \%$ & $9 \%$ \\
\hline $\mathbf{C 5}$ & $7,5 \%$ & $12 \%$ & $7 \%$ & $8 \%$ \\
\hline $\mathbf{C 6}$ & $7,5 \%$ & $7 \%$ & $7 \%$ & $12 \%$ \\
\hline $\mathbf{C 7}$ & $7,5 \%$ & $8 \%$ & $15 \%$ & $8 \%$ \\
\hline $\mathbf{C 8}$ & $10 \%$ & $13 \%$ & $10 \%$ & $9 \%$ \\
\hline
\end{tabular}

S1 has a twice higher impact on the results because he is one of the decision-makers of the studied company. Table 3 shows evaluation weights on the result. Q value, reflecting the minimum weight value of CSFs, is determined \%1. Moreover, the P-value, reflecting the maximum weight value of CSFs, is also determined by $\% 50$. Calculations are made on Microsoft EXCEL. 
Table 3. PROMETHEE Decision Makers Weights

\begin{tabular}{|ccccc|}
\hline & S1 & S2 & S3 & S4 \\
\hline w & $40 \%$ & $20 \%$ & $20 \%$ & $20 \%$ \\
\hline
\end{tabular}

In the progress, each evaluation is normalized, and then preference function (Pi) values are calculated for each specialist evaluation. Next, calculations are combined and multi-criteria preference degrees $(\pi)$ are computed in terms of preference function values and evaluation weights. Results are given in Table 4 After calculations preference degrees, we normalize the $\mathrm{Q}$ results and obtain $f$ values, shown in Table 5. Using $\mathrm{f}$ values, we compute the upper and lower bounds of CSFs weights, given in Table 6.

Table 4. Multi-criteria Preference Degree

\begin{tabular}{|cccccccccc|}
\hline $\boldsymbol{\pi}(\mathbf{C i} \mathbf{C} \mathbf{j})$ & $\mathbf{C 1}$ & $\mathbf{C 2}$ & $\mathbf{C 3}$ & $\mathbf{C 4}$ & $\mathbf{C 5}$ & $\mathbf{C 6}$ & $\mathbf{C 7}$ & $\mathbf{C 8}$ & $\mathbf{Q +}$ \\
\hline $\mathbf{C 1}$ & 0,00 & 0,00 & 0,00 & 0,00 & 0,00 & 0,00 & 0,00 & 0,00 & $\mathbf{0 , 0 0}$ \\
\hline $\mathbf{C 2}$ & 0,49 & 0,00 & 0,20 & 0,44 & 0,43 & 0,43 & 0,41 & 0,39 & $\mathbf{2 , 7 8}$ \\
\hline $\mathbf{C 3}$ & 0,27 & 0,00 & 0,00 & 0,22 & 0,21 & 0,22 & 0,20 & 0,17 & $\mathbf{1 , 2 9}$ \\
\hline $\mathbf{C 4}$ & 0,03 & 0,00 & 0,00 & 0,00 & 0,00 & 0,01 & 0,00 & 0,00 & $\mathbf{0 , 0 4}$ \\
\hline $\mathbf{C 5}$ & 0,04 & 0,00 & 0,00 & 0,00 & 0,00 & 0,02 & 0,01 & 0,00 & $\mathbf{0 , 0 7}$ \\
\hline $\mathbf{C 6}$ & 0,03 & 0,00 & 0,00 & 0,01 & 0,01 & 0,00 & 0,01 & 0,01 & $\mathbf{0 , 0 7}$ \\
\hline $\mathbf{C 7}$ & 0,06 & 0,00 & 0,00 & 0,03 & 0,03 & 0,03 & 0,00 & 0,02 & $\mathbf{0 , 1 6}$ \\
\hline $\mathbf{C 8}$ & 0,08 & 0,00 & 0,00 & 0,03 & 0,02 & 0,04 & 0,03 & 0,00 & $\mathbf{0 , 2 0}$ \\
\hline $\mathbf{Q}-$ & $\mathbf{0 , 9 9}$ & $\mathbf{0 , 0 0}$ & $\mathbf{0 , 2 0}$ & $\mathbf{0 , 7 3}$ & $\mathbf{0 , 7 0}$ & $\mathbf{0 , 7 4}$ & $\mathbf{0 , 6 7}$ & $\mathbf{0 , 5 8}$ & \\
\hline
\end{tabular}

Table 5. Normalize Q Values

\begin{tabular}{|ccccccccc|}
\hline $\mathbf{Q}$ & $\mathbf{C 1}$ & $\mathbf{C 2}$ & $\mathbf{C 3}$ & $\mathbf{C 4}$ & $\mathbf{C 5}$ & $\mathbf{C 6}$ & $\mathbf{C 7}$ & $\mathbf{C 8}$ \\
\hline Q (-) & $0,2 \%$ & $29,6 \%$ & $23,8 \%$ & $7,8 \%$ & $8,8 \%$ & $7,6 \%$ & $9,9 \%$ & $12,3 \%$ \\
\hline Q (+) & $0,0 \%$ & $60,2 \%$ & $27,9 \%$ & $0,9 \%$ & $1,6 \%$ & $1,6 \%$ & $3,5 \%$ & $4,3 \%$ \\
\hline
\end{tabular}


Table 6. CSF Weight Bounds for DEA

\begin{tabular}{|ccccccccc|}
\hline Bounds $(f)$ & C1 & C2 & C3 & C4 & C5 & C6 & C7 & C8 \\
\hline Lower $\left(f^{-}\right)$ & $0,0 \%$ & $29,6 \%$ & $23,8 \%$ & $0,9 \%$ & $1,6 \%$ & $1,6 \%$ & $3,5 \%$ & $4,3 \%$ \\
\hline Upper $\left(f^{+}\right)$ & $0,2 \%$ & $60,2 \%$ & $27,9 \%$ & $7,8 \%$ & $8,8 \%$ & $7,6 \%$ & $9,9 \%$ & $12,3 \%$ \\
\hline
\end{tabular}

\section{Complete Rankings: DEA}

In the pilot study, we examined 5 homogenous departments for the company. Because of company rules, we do not authorize for sharing names of the departments, called $\mathrm{Di}$. CSF results are based on actual results, but we do not use them directly, we manipulated them noticing not to affect the calculations. Table 7 shows the manipulated performance scores. Calculations are made by Solver via VBA on Microsoft EXCEL.

Table 7. Criteria Performance Scores of Departments

\begin{tabular}{|c|c|c|c|c|c|c|c|c|c|}
\hline $\begin{array}{c}\text { Criteria } \\
\text { / Dept. }\end{array}$ & $C 1$ & $C 2$ & C3 & C4 & $C 5$ & C6 & $C 7$ & $C 8$ & $X 1$ \\
\hline$D 1$ & $51 \%$ & $65 \%$ & $48 \%$ & $77 \%$ & $78 \%$ & $75 \%$ & $45 \%$ & $91 \%$ & 1,00 \\
\hline D2 & $88 \%$ & $66 \%$ & $55 \%$ & $66 \%$ & $71 \%$ & $65 \%$ & $39 \%$ & $53 \%$ & 1,00 \\
\hline D3 & $95 \%$ & $85 \%$ & $90 \%$ & $95 \%$ & $44 \%$ & $64 \%$ & $85 \%$ & $81 \%$ & 1,00 \\
\hline D4 & $49 \%$ & $77 \%$ & $81 \%$ & $24 \%$ & $54 \%$ & $91 \%$ & $59 \%$ & $57 \%$ & 1,00 \\
\hline D5 & $62 \%$ & $54 \%$ & $69 \%$ & $61 \%$ & $87 \%$ & $100 \%$ & $57 \%$ & $69 \%$ & 1,00 \\
\hline
\end{tabular}

In the progress, we assumed a single input for all departments, so a dummy input, $X 1$, is valued as 1. Firstly, we applied the DEA CCR (DEA 1) method alone (Table 8), and after that, we applied the DEA CCR method using PROMETHEE (DEA-PR) results (Table 9). Table 10 gives both efficiency scores and rankings. 
Table 8. Efficiency Results and Rankings (DEA CCR)

\begin{tabular}{|l|c|c|}
\hline \multirow{2}{*}{$\begin{array}{l}\text { Dept. } \\
\text { Dept. }\end{array}$} & \multicolumn{2}{|c|}{ DEA1 } \\
\cline { 2 - 3 } D1 & Rank & Efficiency \\
\hline D2 & 4 & $75 \%$ \\
\hline D3 & 5 & $65 \%$ \\
\hline D4 & 2 & $64 \%$ \\
\hline D5 & 1 & $91 \%$ \\
\hline
\end{tabular}

Table 9. Efficiency Results and Rankings (DEA PR)

\begin{tabular}{|l|c|c|}
\hline \multirow{2}{*}{$\begin{array}{l}\text { Dept. } \\
\text { Dept. }\end{array}$} & \multicolumn{2}{|c|}{ DEA-PR } \\
\cline { 2 - 3 } Rank & Efficiency \\
\hline D1 & 3 & $78 \%$ \\
\hline D2 & 5 & $73 \%$ \\
\hline D3 & 1 & $100 \%$ \\
\hline D4 & 2 & $85 \%$ \\
\hline D5 & 4 & $79 \%$ \\
\hline
\end{tabular}

Table 10. Efficiency Results and Rankings (both)

\begin{tabular}{|l|c|c|c|c|}
\hline \multirow{2}{*}{$\begin{array}{l}\text { Dept. } \\
\text { Dept. }\end{array}$} & \multicolumn{2}{|c|}{ DEA1 } & \multicolumn{2}{c|}{ DEA-PR } \\
\cline { 2 - 5 } Rank & Efficiency & Rank & Efficiency \\
\hline D1 & 3 & $75 \%$ & 3 & $78 \%$ \\
\hline D2 & 4 & $65 \%$ & 5 & $73 \%$ \\
\hline D3 & 5 & $64 \%$ & 1 & $100 \%$ \\
\hline D4 & 2 & $91 \%$ & 2 & $85 \%$ \\
\hline D5 & 1 & $100 \%$ & 4 & $79 \%$ \\
\hline
\end{tabular}




\section{Result Findings}

The first DEA application results have completely different than the second application. Moreover, Although D5 is the most efficient department according to first DEA with a $\% 100$ score, $4^{\text {th }}$ department, having $\% 79$ efficiency, in terms of the DEA-PR approach. In contrast, D3 is the last efficient department according to DEA1 results, but the most efficient department in terms of the DEA-PR model.

If we analyze the weight values of both applications, we understand the worth of weight restrictions. When the DEA1 results are examined, it can be seen that its results are the same as the criterion C6 results because the DEA1 model resulted in a weight value of C6 is \%100 and other criteria have $\% 0$ weights. Furthermore, we share the department 5 weight results, obtained by the applications, in Table 8 for example. DEA1, DEA wants to maximize outputs and maximize the most successful CSF weight as $\% 100$. Since we use single input as 1 , it does not have any obstacle to change this tendency. Although there exist some different techniques to limit weight values in the literature, in our model we used PROMETHEE to determine the limits and it provides us obtaining more consistent results

Table 8. Weight Comparison for Dept.5

\begin{tabular}{c|cccccccc} 
Weights & $C 1$ & $C 2$ & $C 3$ & $C 4$ & $C 5$ & $C 6$ & $C 7$ & $C 8$ \\
\hline DEA1 & $0,0 \%$ & $0,0 \%$ & $0,0 \%$ & $0,0 \%$ & $0,0 \%$ & $100,0 \%$ & $0,0 \%$ & $0,0 \%$ \\
$D E A-P R$ & $0,24 \%$ & $47,23 \%$ & $27,85 \%$ & $7,84 \%$ & $8,81 \%$ & $7,60 \%$ & $9,89 \%$ & $12,30 \%$
\end{tabular}




\section{CONCLUSION}

Companies make performance analyses and follow their CSFs for their decision-making process. CSFs' measurements show the weak and strong points, but they ignore the overall performance and ranking issues of DMUs. In the literature, a linear programming-based DEA method is recommended to handle relative comparison and outranking problems.

In the study, we searched how to make a fair and reliable comparison on DMUs. To reach this aim, we use the DEA methodology. However, DEA application that does not consider weight limitation produces inconsistent results. When this situation was analyzed, we find out undesirable weight values causes to deviate objectives. At this point, the PROMETHEE method, which is an MCDM technique, supports and strengths the DEA application.

Our proposed model is applied to a case study. We first work on the PROMETHEE process, after applying computations according to the decision-maker or specialist evaluations on CSFs priorities, we obtained upper and lower weights values of CSFs in DEA. Next, the DEA method is applied twice. At first, the DEA1 procedure is run ignoring weight restriction, and then the second DEA procedure is run by utilizing PROMETHEE findings. Results show that the developed DEA-PROMETHEE model has more consistent results, and also it is more sensitive in terms of efficiency calculations. Our proposal ensures the decision-makers having a judgment opportunity to determine the weight value of the criteria. Furthermore, different decision-makers or specialists make comparison criteria and we provide prioritization chances among the specialists. Moreover, these bounded criteria lead to increase discrimination power of the DEA model, and it produces more logical data. 


\section{REFERENCES}

Alcatraz, G. \& Goridis, C. 1991. Biosynthesis and processing of polysialylated NCAM by AtT-20 cells. European Journal of Cell Biology 55(1): 165-73.

Aladağ, Z., Alkan, A., Güler, E., \& Özdin, Y. 2018. Akademik birimlerin veri zarflama analizi ve promethee yöntemleri ile performans değerlendirmesi: Kocaeli üniversitesi örneği. Erciyes Üniversitesi Fen Bilimleri Enstitüsü Fen Bilimleri Dergisi, 34(1), 1-13.

Albadvi, A., Chaharsooghi, S. K., \& Esfahanipour, A. 2007. Decision making in stock trading: An application of PROMETHEE. European journal of operational research, 177(2), 673-683.

Babaee, S., Bagherikahvarin, M., Sarrazin, R., Shen, Y., \& Hermans, E. 2015. Use of DEA and PROMETHEE II to assess the performance of older drivers. Transportation research procedia, 10, 798-808.

Bagherikahvarin, M. 2019. A DEA-PROMETHEE approach for complete ranking of units. International Journal of Operational Research, 35(2), 224-244.

Bagherikahvarin, M., \& De Smet, Y. 2016. A ranking method based on DEA and PROMETHEE II (a rank based on DEA \& PR. II). Measurement, 89, 333-342.

Brans, Y. W., Huff, R. W., Shannon, D. L., \& Hunter, M. A. 1982. Maternal Diabetes and Neonatal Macrosomia I. Postpartum Maternal Hemoglobin A1c Levels and Neonatal Hypoglycemia. Pediatrics, 70(4), 576-581.

Brans, J. P., \& De Smet, Y. 2016. PROMETHEE methods. In Multiple criteria decision analysis (pp. 187-219). Springer, New York, NY.

Charnes, A., Cooper, W. W. \& Rhodes, E. 1978. Measuring the effciency of decision making units,. European Journal of Operational Research, 2, 429-444

de Sousa, T. B., Melo, I. C., de Oliveira, P. H., Lourenço, C. M., Guerrini, F. M., \& Esposto, K. F. 2020. Balanced scorecard for evaluating the performance of supply chains: A bibliometric study. Journal of Engineering Research, 8(1).

Rouyendegh, B.D. 2011. The DEA and intuitionistic fuzzy TOPSIS approach to departments' performances: a pilot study. Journal of Applied Mathematics, 2011. 
Najafi, E., \& Aryanezhad, M. 2011. A BSC-DEA approach to measure the relative efficiency of service industry: A case study of banking sector. International Journal of Industrial Engineering Computations, 2(2), 273-282.

Safari, H., Fagheyi, M. S., Ahangari, S. S., \& Fathi, M. R. 2012. Applying PROMETHEE method based on entropy weight for supplier selection. Business management and strategy, 3(1), 97-106.

Senel, Ugur Tahsin 2018. Selecting the High-Performing Departments Applying AHP ELECTRE MADM Methods. New Challenges in Industrial Engineering and Operations Management, 50

Şenel, T. U. 2020. Bütünleşik performans değerlendirme yöntemi önerisi ve performans tabanlı bölüm başarı değerlendirmesi: Kurumsal bir şirkette örnek çalışma (Master's thesis, TOBB ETÜ Fen Bilimleri Enstitüsü).

Şenel, U. T., Rouyendegh, B. D., \& Tekin, S. 2020. Integrated performance evaluation method study and performance based department ranking: a case study. SN Applied Sciences, 2(2), 281.

Şenkayas, H., \& Hekimoğlu, H. 2013. Çok kriterli tedarikçi seçimi problemine promethee yöntemi uygulamasi.

Tekez, E., Kar, F., \& Cengiz Toklu, M. 2019. A new model for continuous evaluation of suppliers with real execution data. Journal of Engineering Research, 7(2).

Yurdakul, M., \& Ic, Y. T. 2005. Development of a performance measurement model for manufacturing companies using the AHP and TOPSIS approaches. International Journal of Production Research, 43(21), 4609-4641. 